\title{
¿TURBULETAS O TURDETANOS, EN LA GUERRA DE SAGUNTO?
}

\author{
JOSE UROZ SAEZ \\ Universidad de Alicante
}

\begin{abstract}
Las causas de la segunda guerra púnica han producido una extensa bibliografía desde la Antigüedad y, sin embargo, no ha sido suficientemente aclarado un hecho importante en la conquista de Sagunto, cual es la utilización por Aníbal, en provecho propio, de un viejo contencioso entre la ciudad edetana y la vecina de los turbuletas, como señalan las fuentes.

Les causes de la deuxième guerre punique ont produit une bibliographie copieuse depuis l'Antiquité, mais pourtant un fait important $\mathbf{n}$ 'a pas été suffisamment éclairé dans la conquête de Sagunto, tel qu'est l'utilisation par Anibal, por son prope profit, d'un vieux litige entre la ville édétane et sa voisine des turbolètes, comme ont voit dans les sources.
\end{abstract}

Esta es una vieja cuestión, discutida al menos desde la Edad Moderna por autores (BEUTER, 1563; ESCOLANO, 1610; DIAGO, 1613; FLOREZ, 1860; COSTA, 1891 y 1892; MADOZ, 1845-50) que han of recido soluciones diversas, pero mayoritariamente indentificados con Apiano, llegando incluso a situar a Turba/Turbula en Torres-Torres o en Teruel, aunque hay otros que han apoyado el texto de Livio, con ligeras modificaciones.

\section{LOS TEXTOS DE T. LIVIO}

XXI, 6, 1:

«Cum Saguntinis bellum nondum erat, ceterum iam belli causa certamina cum finitimis serebantur, maxime Turdetanis»».

Aún no había estallado la guerra contra Sagunto, pero ya se promovían conflictos con los pueblos vecinos, causa futura de la guerra, principalmente con los turdetanos.

XXI, 12, 5:

«Postulabatur autem, redderent res Turdetanis traditoque omni auro atque argento egressi urbe cum singulis vestimentis ibi habitarent ubi Poenus iussisset».

Se les pedía, en cambio, que devolviesen a los turdetanos el botín y que, entregado todo el oro y la plata, saliendo de la ciudad con un vestido cada uno, habitasen allí donde el general cartaginés les ordenara.

XXIV, 42, 9-11:

«Cum tam prosperae res in Hispania essent, verecundia Romanos tandem cepit Saguntum oppidum, quae causa belli esset, octavum iam annum sub hostium potestate esse. Itaque id oppidum vi pulso praesidio Punico receperunt cultoribusque antiquis quos ex iis vis reliquerat belli restituerunt; et Turdetanos, qui contraxerant eis cum Carthaginiensibus bellum, in potestatem redactos sub corona vendiderunt urbemque eorum deleverunt». 
Al ver sus victorias en España, les dio vergüenza a los romanos haber dejado ocho años ya, en poder del enemigo, la ciudad de Sagunto, que fuera causa de esta guerra. Por ello, expulsando a la guarnición cartaginesa, recobraron la ciudad y la devolvieron a aquellos habitantes antiguos que habían escapado de las desgracias de la guerra. Y a los turdetanos, que habían puesto en guerra a los saguntinos como los cartagineses, los sometieron, los vendieron como esclavos y arrasaron su ciudad.

XXVIII, 39, 1-12:

«Tum Saguntinorum legatos in senatum introduxit. Ex eis maximus natu: ...P. et Cn. Cornelii... Iam omnium primum oppidum nobis restituerunt; per omnem Hispaniam cives nostros venum datos, ... ex servitute in libertatem restituerunt...

Tum vero ad hoc retracti ex distantibus locis in sedem antiquam videbamur ut iterum periremus et alterum excidium patriae videremus - nec ad perniciem nostram Carthaginiensi utique aut duce aut exercitu opus esse: ab Turdulis nos veterrimis hostibus, qui prioris quoque excidii causa nobis fuerant, exstingui posse- cum ex insperato repente misistis nobis hunc P. Scipionem, ...; postremo Turdetaniam, adeo infestam nobis ut illa gente incolumi stare Saguntum non posset, ita bello adflixit ut non modo nobis sed - absit verbo invidia - ne posteris, quidem timenda nostris esset. Deletam urbem cernimus eorum quorum in gratiam Saguntum deleverat Hannibal; vectigal ex agro eorum capimus quod nobis non fructu iucundius est quam ultione».

Entonces introdujo ante el Senado a los legados de Sagunto. El de más edad dijo: ...Publio y Cneo Cornelio... ante todo nos restituyeron la ciudad, libraron de la servidumbre, devolviéndolos a la libertad a nuestros conciudadanos vendidos por toda España... Pero entonces parecía que habíamos sido sacados de aquellos lugares lejanos y vueltos a nuestra antigua sede para perecer de nuevo y ver una segunda destrucción de la patria - y sin que fuera necesario ningún general o ejército cartaginés para consumar nuestra ruina: pues los Túrdulos, nuestros enemigos de siempre, que ya habían sido causa de nuestro primer desastre, podían aniquilarnos - cuando de repente, sin esperarlo nosotros, nos enviásteis este P. Escipión... Finalmente, en vista de que si quedaba incólume aquella odiada Turdetania no podía Sagunto subsistir, la derribó hasta dejarla incapaz de inspirar temor, no sólo a nosotros — séame permitido decirlo-, sino también a nuestros descendientes. Vimos destruida aquella ciudad en consideración de la cual Aníbal destruyera Sagunto; recibimos de sus tierras un tributo para nosotros más precioso como venganza que como provecho.

\section{XXXIII, 44, 4:}

«Mirantibus iam vulgo hominibus quod cum Hispania movisset bellum neglegerent, litterae a Q. Minucio adlatae sunt se ad Turbam oppidum cum Budare et Baesadine imperatoribus Hispanis signis collatis prospere pugnasse: duodecim milia hostium caesa, Budarem imperatorem captum, ceteros fusos fugatosque».

Cuando ya empezaba la gente a extrañarse de que no se preocupasen de la guerra en Hispania, se recibieron cartas de Q. Minucio según las cuales había combatido con buena fortuna con Budar y Besadines, generales hispanos, junto 
a la ciudad de Turba; doce mil enemigos había caído, el jefe Budar había sido apresado y el resto del ejército se había dispersado.

Los argumentos de quienes apoyan y defienden los textos de Livio se pueden sintetizar y estructurar así: descalificación de Apiano como autor fuente; todos los habitantes al sur del Júcar son turdetanos; puede tratarse de un grupo de turdetanos expulsados del mediodía y asentados al sur de Castellón; y, por último, que los enemigos de Sagunto fueran bastetanos, vecinos de los edetanos, para lo cual en esta época (s. III) no deberían existir aún los contestanos.

\section{1) Descalificación de Apiano}

Un argumento que se esgrime con frecuencia es el de que debe preferirse el texto de Livio al de Apiano, porque éste comete errores en materia de nombres geográficos y étnicos: confunde Baécula y Bética, degenera Carmonem en Carbonem o Narbonem, Contrebia en Complegan (VALLEJO, 1943, p. 154, y 1946, pp. XIX-XX).

Sin embargo, esta opinión debe matizarse convenientemente, pues no es precisamente Livio un autor que destaque por sus precisiones, libre de faltas (ANDRE-HUŚ, 1975). Por citar algunas, en el libro XXI establece la caída de Sagunto en el año 218 a. C. En realidad, no se trataría de un error involuntario, sino un falseamiento intencionado por motivos políticos (KLOTZ, 1941) para poder justificar la carencia de auxilio romano a la ciudad aliada hasta esa fecha, o bien un arreglo del texto a consecuencia de haberse tropezado con una contradicción (VALLEJO, 1943, p. 150). Confunde la fecha exacta de la celebración de los primeros juegos de Megalesia: en XXXIV, 54, 3 la atribuye al año 194, y en cambio en XXXVI, 36 afirma que el suceso se produjo en 191. La narración liviana (XXII, 20, 3) de las acciones romanas al sur del Ebro en el 217 antes de la llegada de Publio Escipión se tiene por pura fantasía (ROLDAN, 1978, p. 39; KAHRSTEDT, 1913, p. 457; DE SANCTIS, 1916, p. 247). Confusión de Livio es la propia mención de turdetanos en estos pasajes analizados (UKERT, 1821, p. 308; ROESINGER, 1864, p. 5; BOSCH GIMPERA-AGUADO BLEYE, 1962, pp. 14-15), que puede deberse a su desinterés en estudiar los lugares que describe así como a una falta de análisis riguroso y comparativo de sus fuentes de información, lo que le hace caer en contradicción en no pocas ocasiones (ANDRE-HUS, 1975, pp. 91 y ss.). Incluso se ha llegado a afirmar (VALLEJO, 1943, pp. 162 y 168; Idem, 1946, p. XXV) que la intervención de los turdetanos en el conflicto de Sagunto no es más que una invención, bien total, bien limitada a la elección del nombre.

\section{2) Los turdetanos se extienden hasta el Júcar}

Es opinión de los defensores de tal teoría que desde el Júcar hasta Lusitania, Roma no encontró más enemigo que los turdetanos; ni los oretanos ni bastetanos tienen significación histórica o arqueológica (VALLEJO, 1943, pp. 161 y 164; Idem, 1946, pp. XXII-XXIV). Para VENTURA (1972, p. 2), el Júcar (que sería el río Ibero) es el límite norte de los turdetanos; este río separó el territorio de los turdetanos (al S.) de los edetanos (al N.). Las palabras «Turdetania» 
y «turdetanos» se emplean en sentido amplio para designar a toda la gente no ibera del sureste y del sur de Hispania; el SE. interior se caracteriza por habitarlo una población no ibera y con acentuadas notas turdetanas, y al mismo tiempo, sin verdadera personalidad guerrera o política (VALLEJO, 1943, p. 167); Idem, 1946, p. XXIX).

Efectivamente, el turdetano fue un pueblo importante, pero no hasta el extremo de quererlo hacer llegar hasta el Júcar, cuando sabemos que sólo ocupaba una amplia franja a lo largo del curso medio y bajo del Guadalquivir.

Actualmente no se puede mantener ni un solo punto de esta tesis, que no merece más comentarios, pues ignora totalmente la existencia de los contestanos, bien conocidos ya (LLOBREGAT, 1972; UROZ, 1981). De la significación histórica o arqueológica de los oretanos y bastetanos bástenos tan sólo con citar a Cástulo (BLAZQUEZ, 1975 y 1979; BLAZQUEZ-VALIENTE, 1981), Oreto (NIETO-SANCHEZ MESEGUER, 1980; CONTRERAS, 67-71) y el yacimiento que ha proporcionado la excepcional Dama de Baza (PRESEDO, 1973), además de las noticias trasmitidas por las fuentes. Los turdetanos meridionales no pudieron ser los enemigos de Sagunto, como ya observó ROESINGER (1864), quien además niega que se llamara Turdetania la nación rival de los saguntinos.

$\mathrm{Al}$ margen de estas consideraciones, la lógica y razón se oponen a quienes argumentan en favor de Livio. Por mucho que se quiera estirar a los turdetanos, no pueden llegar hasta el Palancia; y en esto son categóricas las fuentes, incluso Livio: son gentes vecinas de Sagunto. Además, cualquier enemigo que venga desde el sur para enfrentarse con Sagunto ha de atravesar todo el territorio edetano (UROZ, 1980). No se entiende tampoco que los saguntinos hubieran ido a Andalucía a combatir y coger botín a los turdetanos en los momentos anteriores a su cerco por Aníbal, cuando los bárkidas dominaban ya toda la región, porque se tendrían que haber enfrentado también a éstos. Si los enemigos de Sagunto fueran los turdetanos del mediodía, ellos solos hubieran podido aplastar a la ciudad levantina, sin necesitar la mediación de Aníbal. Tampoco se entiende que una sola ciudad, Sagunto, pudiera tener como tributario al gran pueblo turdetano (sobre todo si era tan importante que llegaba hasta el Júcar), ni que los turdetanos y saguntinos fueran «enemigos de siempre», pues no tenían intereses comunes o contrapuestos y mediaban entre ellos las tribus bastetana, oretana, contestana y edetana. Sin duda alguna, este pueblo enemigo de Sagunto vivía en una ciudad (que Livio equivocadamente denomina Turdetania y Turda/Turba), destruida la cual por Escipión se terminó el problema para Sagunto (Livio, XXVIII, 39), y esto no puede encajar con los turdetanos, que poseían muchas ciudades.

A la identificación de los turdetanos livianos con los turdetanos clásicos se oponen los mismos textos de Livio:

$\mathrm{XXI}, 6,1$ :

«...cum Saguntinis bellum nondum erat, ceterum iam belli causa certamina cum finitimis serebantur».

XXI, 12, 5:

«...Postulabatur autem (Saguntinis), redderent res Turdetanis». 
XXIV, 42, 11:

"...et Turdetanos, qui contraxerant eis cum Carthaginiensibus bellum, in potestatem redactos sub corona vendiderunt urbemque eorum deleverunt».

XXVIII, 39, 8:

«...ab Turdulis nos veterrimis hostibus, qui prioris quoque excidii causa nobis fuerant...»

XXVIII, 39, 11:

«...postremo Trudetaniam, adeo infestam nobis ut illa gente incolumi stare Saguntum non posset, ita bello adflixit (Escipión) ut non modo nobis sed - absit verbo invidia- ne posteris quidem timenda nostris esset».

XXVIII, 39, 12:

«Deletam urbem cernimus eorum quorum in gratiam Saguntum deleverat Hannibal; vectigal ex agro eorum capimus quod nobis non fructu iucundius est quam ultione».

Es decir, en Livio:

a) los enemigos de Sagunto son pueblos vecinos

b) los saguntinos habían cogido botín a los turdetanos

c) turdetanos y saguntinos habían sido siempre enemigos

d) Sagunto sólo podía subsistir si se destruía la ciudad enemiga

e) después de la destrucción, sus tierras pagaron un tributo a Sagunto

f) los turdetanos fueron la causa de la guerra entre Cartago y Sagunto

g) los romanos arrasaron su única ciudad y los vendieron como esclavos

Evidentemente, no se puede referir a los turdetanos del sur.

\section{3) Un grupo de turdetanos asentados al sur de Castellón}

Ya a principios del siglo XVII el P. DIAGO (1613, t. I, pp. 92-3) propugnaba que la Turdetania que se menciona en los textos livianos no se refería a la de Andalucía, pues en su opinión la capital de estos Turdetanos estuvo en TorresTorres, nombre actual de la antigua Turdetania. A finales del XIX, J. COSTA (1895, p. 143 y ss.), a quien seguieron SARTHOU CARRERES (s. a., p. 704), M. PERIS (1922, p. 356) y VALLEJO (1943, pp. 164-5) mantenía y desarrollaba la teoría en estos términos: un grupo de turdetanos del Guadalquivir, expulsados por los gaditanos y cartagineses, se instala al sur de la Plana de Castellón; la capital de la Turdetania debería estar en Onda, y se extiende por Segorbe, Viver, Jerica, Begis, Burriana, Almazora y Lucena; el río Palancia se llamó Baetis en época iberromana, y de ahí se originó Bejís, nombre dado por los árabes al nacimiento del río.

Pero nada hace pensar que fueran iberos los enemigos de Sagunto, más bien parece tratarse de gentes celtíberas. En el año 219 Aníbal domina a los carpetanos, olcades, edetanos, sin traspasar todavía el Palancia. Y conocemos por Polibio (III, 17, 2) que Sagunto alcanza por el Oeste hasta territorio Celtíbero.

La identificación Baetis-Palancia no se puede mantener, y mucho menos la 
ubicación de unas gentes al norte de Sagunto, pues sabemos por las fuentes (Plinio III, 20) que los edetanos en este lugar limitan directamente con los ilercavones.

Una Turdetania que dominara desde Almanzora a Viver sería incluso más extensa que el Municipium Saguntinum (F. BELTRAN, 1980). Es asimismo difícil de creer que Livio se refiera dentro del mismo libro a dos pueblos distintos, pero del mismo nombre, sin avisar nunca tan curiosa particularidad. Por lo tanto, habrá que valorar convenientemente la tesis que propugna (BAYERRI, 1948), leer Turolani, Turbitanos, Turbetanos, Turbuli, en vez de Turdetani, Turditanos, Turdetanos y Turduli respectivamente. O quizás aceptar que la intervención de los turdetanos es una simple invención de una fuente anterior a Livio, o yerro de éste (GROAG, 1929).

\section{4) Turbula, ciudad bastetana}

En reciente publicación, BELTRAN Y SANCHO (1979, p. 311) expresaban la posibilidad de que siendo bastetanos los turboletas, al no tener constancia de los contestanos en el siglo III, bastetanos y edetanos fueran vecinos; los bastetanos se extenderían más al norte, y esto explicaría la denominación de turduli o turdetani de Livio, pues en esta época debería de haber cierta confusión entre éstos y los bastetanos.

Es cierto que Ptolomeo cita a Turbula como ciudad bastetana, pero no lo es menos que por las coordenadas geográficas que da hay que situarla al NO. de Sagunto, y hasta allí no se les puede hacer llegar a los bastetanos de ningún modo. Sería más fácil de creer que Ptolomeo, o sus copistas, por error, la colocara en otra tribu distinta. Confusiones semejantes no son infrecuentes en dicho autor: sitúa a Valentia entre los contestanos, Dianium entre las ciudades edetanas al N. de Sagunto, a Lucentum en la Bastetania al S. de Cartago Nova; igual ocurre fuera de Hispania (BARRUOL, 1969).

Tito Livio denomina indistintamente turdetanos o turdulos, pero en modo alguno los confunde con los bastetanos (XXXVII, 46, 7). Es obvio que se trate de pueblos distintos.

Por otra parte, no se puede cuestionar la existencia de los contestanos por el simple hecho de que son mencionados en fuentes tardías (Plinio III, 19; Ptolomeo II, 6, 14 y II, 6, 62) como ya ha quedado demostrado (LLOBREGAT, 1972; UROZ, 1981); en todo caso, son las mismas fuentes que utilizamos para estudiar la mayoría de los pueblos prerromanos. Y, en fin, no hay que perder de vista que no estamos ante un conflicto entre turdetanos y edetanos, o edetanosbastetanos, sino entre la ciudad de Sagunto y otra ciudad vecina, por intereses económicos comunes probablemente.

\section{EL TEXTO DE APIANO}

Sobre Iberia, 10: «Convenció (Aníbal) a los turbuletas, que eran vecinos de los saguntinos, de que se le quejasen de que éstos les devastaban los campos y les infligían otros muchos ultrajes, y obedecieron ellos. Entonces, Aníbal envió unos embajadores de éstos a Cartago... hasta que el Senado le autorizó a que ac- 
tuase con los saguntinos del modo que juzgara oportuno. Así, tan pronto como tuvo ocasión, hizo que los turbuletas se presentasen ante él de nuevo con quejas de los saguntinos, y mandó venir embajadores de éstos. Llegaron los embajadores saguntinos y, al pedirles Aníbal que cada uno expusiera en su presencia las causas de sus diferencias, éstos contestaron que remitirían el juicio a Roma».

Esta fuente se encuentra apoyada por Ptolomeo que, como ya vimos, menciona la ciudad de Turbula $(I I, 6,60)$ al NO. de Sagunto.

También Livio cita dicha ciudad (XXXIII, 44, 4), aunque bajo la forma Turdam y Turbam. La grafía Turdam aparece en el «codex Bambergensis», del siglo XI, mientras que la forma Turbam lo hace en un códice atribuido al siglo IX, editado en Maguncia en 1519, hoy perdido, y que contenía el texto de los libros XXXIII, 17, 6 a XL. Como Turbam se nos presenta en las ediciones muy pulcras y revisadas de Nicholae Carbachius. Se desconoce la situación exacta de la ciudad, pero debió estar sin duda en la Hispania Citerior (FATAS, 1973, pp. 141-2). La Turbula ptolemaica y la Turba de Livio son para SCHULTEN (1935, p. 28) la misma ciudad.

En ayuda de Apiano vienen también los pasajes de Polibio III, 15, 8:

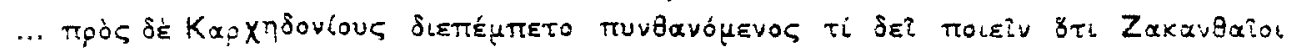

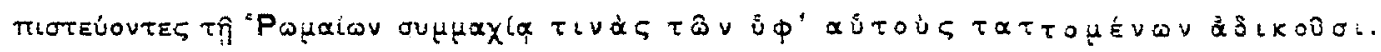

y de Zonaras 9, 3, 8:

of $\delta \dot{\varepsilon}$

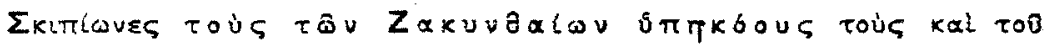

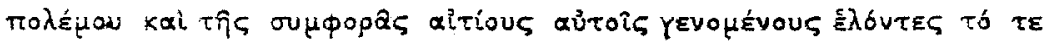

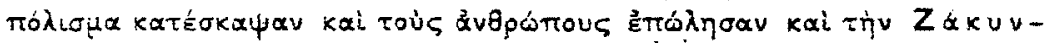

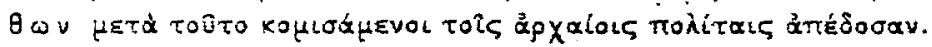

e incluso los mismos de Livio ya citados, interpretados correctamente.

Sin entrar en la discusión de las causas de la Segunda Guerra Púnica (Apiano, Iber. 8-9; Polibio, III, 6-9) y aun dando por supuesto que el tratado del Ebro dejaba las manos libres a Cartago para anexionarse Sagunto, es incuestionable que Aníbal en aquellas circunstancias prefiere no tomar la iniciativa en la ruptura de la paz y maniobra ante el senado cartaginés para buscar la excusa que le obligue a intervenir ante la ciudad edetana, y el motivo lo halla en el contencioso fronterizo existente desde antiguo entre Sagunto y una ciudad vecina, perteneciente a los turbuletas, situada en el mismo valle del Palancia en opinión de P. BELTRAN (1959).

\section{LOS TURBULETAS}

Los turboletas, que son los turones o turos (ALMAGRO BASCH, 1977) que se mencionan en las inscripciones celtibéricas de Peñalba de Villastar (UNTERMANN, 1977), representan para BOSCH GIMPERA (1956-57, p. 132) la dislocación de un pueblo importante perteneciente al penúltimo contingente de los celtas llegados al centro de España y dispersado por los belgas, recluyéndose en torno a la región de Teruel, extendiéndose hacia la costa mediterránea, buscando la salida al mar. Limitarían con los edetanos en la sierra de Javalambre, pero este límite fue desbordado repetidas veces por los turboletas que desde Teruel invadieron por el camino de Sarrión y El Toro el valle del Palancia, donde el nombre céltico de Segorbe (Segóbriga: fortaleza de la victoria) y quien sabe si 
el mismo Sagunto (de la raíz seg-, victoria), parece indicar un dominio más o menos prolongado. Los edetanos, sin embargo, se sobrepusieron a estas infiltraciones, aunque se repitieron hasta los tiempos de las guerras púnicas en que el pretexto de la intervención de Aníbal en Sagunto parece haber sido las luchas de los saguntinos con los turboletas invasores (BOSCH, 1932, pp. 551-2; Idem, 1939, p. 89; Idem, 1944, p. 129; Idem, 1948, p. 85; Idem, 1950-51 y 52-53, p. 124; Idem, 1953, pp. 187-193).

La frontera en el Alto Palancia se admite (ALMAGRO BASCH, 1965; FATAS, 1973, p. 56; ROLDAN, 1978, p. 291) pero Segóbriga (Plinio III, 25; XXXVI, 160; Estrabón III, 4, 13; Frontino, 3, 10, 6; 3, 11, 4) no puede identificarse con Segorbe (P. BELTRAN, 1953; FERNANDEZ NIETO, 1968-69; GARCIA Y BELLIDO, 1977) y la urna hallada en Arañuel, testimonio para BOSCH (1915-20, p. 625; 1924; 1932, pp. 372-3 y 495; 1953, pp. 187-193) de la penetración celta-turboleta en el valle del Palancia, no es tal, sino ibérica (FLETCHER, 1964; JULLY-NORDSTROM, 1966).

Sin embargo, no se ha impugnado la vinculación con la raíz seg-céltica de Sagunto y Segorbe, ni tampoco las relaciones con el mundo céltico peninsular del sufijo - $n t$ (HUSBSCHMID, 1960; ESTEVE, 1978; KRAHE, 1954; UNTERMANN, 1963), presente en Saguntum y Palantia, aunque la identificación de éste con el Palancia resulte problemática. Y por otra parte, recientemente se han publicado (MATA, 1978) unos materiales procedentes de Arañuel cuya vinculación céltica no ofrece dudas.

Además de éstos, aparecen en la zona elementos característicos de la cultura material indoeuropea: en Sagunto, cerámica excisa o con decoración de acanalados (ALMAGRO GORBEA, 1977; Idem, 1979); en la Peña de las Majadas (El Toro), cerámica céltica de la primera Edad del Hierro decorada con incisiones y triángulos excisos (SARRION, 1978) junto a material ibérico y alguna moneda celtibérica. Urnas de cuerpo esferoidal, semejantes a las de Boverot, ollas decoradas con cordones digitados, a veces con fuerte carena, fíbulas de doble resorte, cerámica de superficie espatulada y decoración incisa, y otras semejantes a las del Bajo Aragón ha prospectado SARRION (1975) en los yacimientos cercanos de Cueva Honda (Cirat), Cueva del Mojón Terrer (Montán) y Monte del Calvario (Montán), donde existe un poblado y una necrópolis.

La lingüística también ofrece ejemplos del dominio celtibérico en el valle del Palancia y sus proximidades. Recientemente ha sido publicada una inscripción (ARASA, 1977) latina hallada en Algimia de Almonacid: ASTEDUMAE / $A$ (NNORUM) $L X X X H S E$. Es un nombre de mujer indígena latinizado. ALBERTOS (1966, p. 38) relaciona este radical $A S T$ - con los vocablos indoeuropeos «AST $(\mathrm{H}) »(=$ duro); además la «m» intervocálica es rara en la onomástica ibérica, aunque es corriente en Enserune, en la lengua gala y en nombres ligures. Recuerdo de su pasado céltico son topónimos como Berro, que deriva de «beruron» (LAFUENTE, 1973), y que permanece en Fuente del Berro (Arcos de las Salinas y Altura), o como El Hito (Albentosa). En relación con este avance celtíbero hacia el Mediterráneo hay que explicarse la existencia en Sagunto de un magistrado llamado Biulacos, nombre de incuestionable procedencia indoeuropea, sin relación en el contexto saguntino (UNTERMANN, 1963, p. 186).

Cuestión no menos interesante es la posible persistencia de la frontera 
turboleta-edetana en la línea de delimitación de las zonas de habla castellana y valenciana (BOSCH, 1953, pp. 192-3), así como la etimología de Teruel, cuya evolución ha debido ser Teruel--Terolus--Torolus--Turolus (VENTURA, 1972, pp. 94-99), denominación antigua recogida en Rodrigo Jiménez de Rada (11701247), y que se compone del sufijo diminutivo latino -olus, y la raíz Tur-, indoeuropea para algunos (PALOMAR, 1957; ALBERTOS, 1966, pp. 236-240) y preindoeuropea para otros (FLETCHER, 1962). La identificación de Turba con la ciudad de Teruel, como se ha pretendido (CARCOPINO, 1968; ETIENNE, 1974), es en cambio menos defendible, y resulta demasiado alejada de Sagunto.

Todavía más difícil aún resulta poder diseñar los límites, siquiera aproximados, de estas gentes a fines del siglo III a. C., que deben aguardar a que dispongamos de un más preciso conocimiento, principalmente arqueológico, de la zona, labor que se ha iniciado ya.

\section{BIBLIOGRAFIA}

ALBERTOS FIRMAT, M. L. (1966), La onomástica personal primitiva de Hispania Tarraconense y Béti$c a$, CSIC, Salamanca.

ALMAGRO BASCH, M. (1965), Prólogo a la obra de F..Pallarés, San Antonio de Calaceite, Bordighera, p. 3-4.

- (1977) «Las tierras de Teruel antes de la reconquista cristiana», Teruel, 57-58, pp. 54-57.

ALMAGRO GORBEA, M. (1977), «El Pic dels Corbs, de Sagunto y los campos de urnas del NE. de la Península Ibérica», Saguntum, PLA de Valencia, 12, pp. 89-144.

- (1979) «Cerámica excisa en Sagunto. Una hipótesis sobre el origen de esta ciudad», Saguntum, $P L A$ de Valencia, 14, pp. 97-108.

ANDRE, J. M. - HUS, A. (1975) La historia en Roma, Siglo XXI, Buenos Aires.

ARASA GIL, F. (1977) «Nueva inscripción latina en Algimia de Almonacid, Alto Palancia (Castellón). Algunas notas sobre la onomástica prerromana», $C P A C, 4, \mathrm{pp} \cdot 321-325$.

BARRUOL, G. (1969) Les peuples prérromains du sud-est de la Gaule, E. de Boccard, París, pp. 24 y ss.

BAYERRI, E. (1948) Historia de Tortosa y su comarca, t-V, Tortosa, p. 410.

BELTRAN LLORIS, F. (1980) Epigrafía latina de Saguntum y su territorium, SIP, Trabajos varios, 67.

BELTRAN LLORIS, F. y SANCHO ROCHER, L. (1979) Consideraciones acerca de la población antigua de la mitad meridional de los conventos Cesaraugustano y Tarraconense», Caesaraugusta, 47-48, pp. 307-322.

BELTRAN VILLAGRASA, P. (1953) «Segóbriga», $A P L I V$, SIP, Valencia, pp. 231-253.

- (1959) «Un episodio poco divulgado de la Historia del Municipium Saguntinum», Arse 3, p. 5.

BEUTER, P. A. (1563) Primera parte de la Crónica general de toda España, Valencia, lib. I, cap. XVIII, folio 54.

BLAZQUEZ, J. M. (1975) Castulo I, Acta Arqueológica Hispánica, 8, Madrid (1979).

- Castulo II, EAEsp. 105, Madrid.

BLAZQUEZ, J. M. - VALIENTE, J. M. (1981) Castulo III, Madrid.

BOSCH GIMPERA, P. (1915-20) «L'estat actual del coneixement de la civilizació iberica al regne de Valencia», Anuari del Institut d'Estudis Catalans, VI.

- (1924) «Els problemes arqueollógics de la provincia de Castelló», BSCC, Castellón de la Plana.

- (1932) Etnología de la península ibérica, Arqueología i art ibèrics, Barcelona.

- (1939) Two Celtic Waves in Spain, The Sir John Rhys Memorial Lecture.

- (1944) El poblamiento antiguo y la formación de los pueblos de España, Imprenta Universitaria, México.

(1948) «Los iberos», Cuadernos de «Historia de España»IX, Sección Española del Instituto de Investigaciones Históricas, Buenos Aires.

- (1950-51 y 1952-53) «Les mouvements celtiques. Essai de reconstitution», Etudes celtiques V, VI, París. 
- (1953) «Las urnas de Boverot (Almazora, Castellón) y las infiltraciones célticas en tierras valencianas", $A P L I V$, Valencia, SIP.

- (1956-57) «Ibères, Basques, Celtes», Orbis, Bulletin International de Documentation linguistica, t-V, núm. 2, 1956 y t-VI, núm. 1, 1957.

BOSCH GIMPERA, P. - AGUADO BLEYE, P. (1962) «La conquista de España por Roma», en R. Menéndez Pidal, Historia de España II, España Romana, Espasa Calpe, Madrid.

CARCOPINO, J. (1968) Las etapas del imperialismo romano, Paidos, Buenos Aires, pp. 66-7.

CONTRERAS, R. «La Oretania», Oretania 8-9, pp. 66-71.

COSTA, J. (1892) «Antigüedades ibéricas. Tribus, ciudades y aldeas», El Archivo VI, Denia, p. $76 \mathrm{y}$ ss.

- (1895) «Estudios ibéricos», pp. 123-5 y 143 y ss.

DE SANCTIS, G. (1916) Storia dei Romani, t-III, Torino.

DIAGO, F. (1613) Anales del Reino de Valencia, Valencia, lib. III, cap. XVI, t-I, pp. 92-3.

ESCOLANO, G. (1610) Décadas, L. VII, cap. LXXXI, 7.

ESTEVE, J. (1978) Valencia, fundación romana, Valencia, pp. 111 y ss.

ETIENNE, R. (1974) Le culte imperial dans la Peninsule Iberique, París, p. 42.

FATAS, G. (1973) La Sedetania, Zaragoza.

FERNANDEZ NIETO, F. J. (1968-69) «Beribraces, edetanos e ilercavones (Pueblos prerromanos en la actual provincia de Castellón)», Zephyrus $X I X-X X$, pp. 132.

FLETCHER VALLS, D. (1962) «Algunas consideraciones sobre el nombre Tyris», $P L A, 1$, Valencia, pp. 53-59.

- (1964) «Las urnas de orejetas perforadas», VIII CNA, Zaragoza, pp. 305-319.

FLOREZ, E. (1860) España Sagrada, t-IX, p. 9-10.

GARCIA Y BELLIDO, A. (1977) La España del siglo I de nuestra Era (según P. Mela y C. Plinio), Espasa Calpe, Austral, Madrid, p. 239.

GROAG, E. (1929) Hannibal als Politiker, Viena.

HUSBSCHMID, I. (1960) «Toponimia prerromana», ELH, I, Madrid, pp. 447-499.

JULLY, J. J. - NORDSTROM, S. (1966) «Les vases à oreillettes perforées en France et leur similaires en Méditerranée Occidentale», $A P L, \mathrm{XI}$, pp. 99-125.

KAHRSTEDT (1913) Geschiche der Karthager, vol. III, Berlín.

KLOTZ, A. (1941) «Livius und seine Vorgänger», Heft, 2, pp. 121 y ss.

KRAHE, H. (1954) Sprache und Vorzeit, Heidelberg, pp. 48-63.

LAFUENTE PEREZ, T. (1973) «Toponimia de la comunidad de Albarracín», Teruel, 49-50, p. 195.

LLOBREGAT CONESA, E. (1972) Contestania ibérica, IEA, Alicante.

MADOZ, P. (1845-50) Diccionario geográfico-estadístico-histórico de España y sus provincias de Ultramar, Madrid, t-XV, pp. 103-4.

MATA, C. (1978) «La Cova del Cavall y unos enterramientos en urnas de Liria (Valencia)», $A P L C X$, Valencia, p. 124.

NIETO, G. y SANCHEZ MESEGUER, J. (1980) Oreto I, EAEsp. 114, Madrid.

PALOMAR LAPESA, M. (1957) La onomástica personal prelatina de la antigua Lusitania, CSIC, Salamanca, pp. 107-8.

PERIS, M. (1922) «Sagunto II, Dominio Turdetano», BSCC, t-III, n. ${ }^{\circ} 21$.

PRESEDO VELO, F. (1973) «La Dama de Baza», Trabajos de Prehistoria, vol. 30, Madrid.

ROESINGER (1864) De veteris Hispaniae rebus quibusdam geographicis: $I$, de Turdetanis Saguntinorum inimicis, Schweidmitz, pp. 5-6.

ROLDAN, J. M. (1978) «Cartago y Roma en la Península Ibérica», en Historia de España Antigua, II, Hispania Romana, Cátedra, Madrid.

SARRION MONTAÑANA, I. (1975) «Restos de la Primera Edad del Hierro en la Cueva Honda de Cirat (Castellón)», Lapiaz, Boletín de Información Espeleológica núm. 2, Valencia.

- (1978) «El poblado ibérico de la Peña de las Majadas (El Toro, Castellón de la Plana)», $A P L X V$, Valencia, pp. 177-189.

SARTHOU CARRERES, C. «Provincia de Valencia», en Carreres Candi, Geografía General del Reino de Valencia, t-II.

SCHULTEN, A. (1935) Fontes Hispaniae Antiquae, vol. III.

UKERT (1821) Geographie del Griechen und Römer, II, p. 308.

UNTERMANN, J. (1963) «Estudio sobre las áreas lingüísticas pre-romanas de la Península Ibérica», $A P L X$, SIP, Valencia.

(1977) «En torno a las inscripciones rupestres de Peñalba de Villastar», Teruel, 57-58, pp. 5-21.

UROZ SAEZ, J. (1980) La regio Edetania en la época ibérica, Tesis Doctoral, en prensa.

(1981) Economía y sociedad en la Contestania ibérica, IEA, Alicante.

VALLEJO, I. (1943) «Cuestiones hispánicas en las fuentes griegas y latinas», Emerita XI, pp. $142-179$. (1946) Tito Livio, libro XXI, CSIC, Madrid.

VENTURA, A. (1972) «Notas sobre Teruel antiguo y medieval», Teruel, 47, pp. 83-99. 